\title{
TAUROMAQUIA, VIOLÊNCIA E DESENVOLVIMENTO Opiniões e evidências
}

\author{
Luís Capucha \\ Instituto Universitário de Lisboa, ISCTE-IUL
}

Luís Pereira

Mestre em Desenvolvimento, Diversidades Locais e Desafios Mundiais, ISCTE-IUL

Tiago Tavares

Master in Finance, INDEG/ISCTE

\begin{abstract}
Resumo A respeito da tauromaquia tem vindo a ser difundida a ideia de que a participação ou assistência de crianças a espetáculos tauromáquicos (considerados uma prática anacrónica, uma reminiscência do passado indigna das sociedades modernas) prejudica o seu desenvolvimento psicológico e incentiva comportamentos violentos. Alguns organismos internacionais emitiram opiniões no mesmo sentido. O presente artigo pretende, de forma modesta e sem polemizar em torno do assunto, testar a base de sustentação empírica destas afirmações. Para isso construiu-se um índice de atividade tauromáquica que dá conta da intensidade da presença da tauromaquia em cada concelho de Portugal, o qual foi correlacionado com o índice de poder de compra (aproximação ao nível de desenvolvimento concelhio) e a taxa de criminalidade (aproximação aos putativos efeitos psicológicos da tauromaquia). Verificou-se que não existe correlação significativa entre as variáveis analisadas, isto é, o teste não revelou evidências de relação entre a assistência ou participação ativa na tauromaquia, por um lado, e o desenvolvimento e a criminalidade, nomeadamente a criminalidade que envolve violência, por outro lado.
\end{abstract}

Palavras-chave: tauromaquia, desenvolvimento, violência.

Bullfighting, violence and development: opinions and evidence

Abstract The argument that the participation or attendance of children in bullfights (considered as an anachronistic practice, reminiscent of the past unworthy of modern societies) impairs their psychological development and encourages violent behaviour, is being disseminated in recent years. Some international bodies have also issued similar opinions. The present article intends, in a modest way and without controversy around the subject, to test the bases of empirical sustentation of such argument. For this purpose, has been constructed a "bullfighting activity index" that shows the intensity of the presence of bullfighting in each county of Portugal. This index has been correlated with the purchasing power index (approximation to the level of development of the county) and the crime rate (approximation to the putative psychological effects of bullfighting). It was found that there is no significant correlation between attendance or participation in bullfighting activities, on one hand, and levels of development and crime, including violent crime on the other hand.

Keywords: bullfight, development, violence.

Tauromachie, violence et développement: opinions et évidences

Résumé À propos de la tauromachie, certains défendent l'idée selon laquelle la présence d'enfants à des spectacles tauromachiques (considérés comme une pratique anachronique, une réminiscence du passé indique des sociétés modernes) nuit à leur développement psychologique et les incite à avoir des comportements violents. Plusieurs organismes internationaux ont même rendu des avis en ce sens. Sans vouloir polémiquer autour de la question, cet article s'efforce modestement de tester la base empirique sur laquelle s'appuient ces affirmations. L'auteur a construit pour cela un indice d'activité tauromachique qui rend compte de l'intensité de la présence de la tauromachie dans chaque municipalité du Portugal, afin de savoir s'il existe un lien avec le pouvoir d'achat (approche du niveau de développement municipal) et le taux de criminalité (approche des potentiels effets psychologiques de la tauromachie). Aucune corrélation significative n'a pu être établie entre les variables analysées. Autrement dit, le test n'a révélé aucune relation entre la présence ou la participation active aux spectacles de tauromachie, d'une part, et le développement économique et la criminalité, d'autre part, notamment la criminalité violente.

Mots-clés: tauromachie, développement, violence. 
Resumen A razón de la tauromaquia se ha venido difundiendo la idea de que la participación o asistencia de niños a espectáculos tauromáquicos (considerados una práctica anacrónica, una reminiscencia del pasado indigna de las sociedades modernas) perjudica su desarrollo psicológico e incentiva comportamientos violentos. Algunos organismos internacionales emitieron opiniones en el mismo sentido. El presente artículo pretende, de forma modesta y sin polemizar en torno del asunto, probar la base de sustentación empírica de estas afirmaciones. Para eso se construye un índice de actividad tauromáquica que informa de la intensidad de la presencia de la tauromaquia en cada municipio de Portugal, el cual fue correlacionado con el índice de poder de compra (aproximación al nivel de desarrollo del municipio) y la tasa de criminalidad (aproximación a los presuntos efectos psicológicos de la tauromaquia). Se verificó que no existe correlación significativa entre las variables analizadas; esto significa que la prueba no reveló evidencias de relación entre la asistencia o participación activa en la tauromaquia, por un lado, y el desarrollo y la criminalidad, específicamente la criminalidad que involucra violencia, por otro lado.

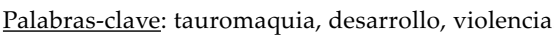

\section{Introdução}

A controvérsia entre pessoas que apreciam corridas de toiros e pessoas que pretendem proibi-las tem, pelo menos nos registos escritos, mais de 500 anos (Guillaume-Alonso, 1999) e percorre toda a geografia taurina, de França à Califórnia e da Península Ibérica aos países latino-americanos onde se pratica a tauromaquia (Colômbia, Equador, México Peru, e Venezuela). Os argumentos das organizações que pretendem proibir as festas de toiros são, mais ou menos, os mesmos desde os primeiros libelos acusatórios e desde as proibições que se registaram em Portugal e Espanha (prosseguidas ainda hoje e recentemente concretizadas em determinados locais ou regiões) nos séculos XVIII e XIX.

De um lado considera-se a festa de toiros uma manifestação que revela e releva de défices civilizacionais, de barbárie e do cultivo de instintos violentos entre povos ou populações "mais atrasados". Representa, nesta perspetiva, uma indignidade praticada por pessoas que se divertem com um espetáculo violento em que um animal é levado ao sofrimento para gozo de uma audiência idêntica à dos circos romanos. Veja-se, para ilustrar este tipo de argumentos, por exemplo, o manifesto "A Momentosa Questão dos 'Touros de Morte' em Portugal", publicado em Lisboa em 1933 em nome das associações de proteção dos animais (Dos Santos e outros, 1933). Uma consulta ao blogue do Movimento de Abolição da Tauromaquia em Portugal (MAPT) (matportugal.blogspot.pt, consultado em 31 de março de 2018) permite verificar como este movimento, tomado aqui apenas como exemplo, elege como referência da sua ideologia básica a frase, atribuída a Passos Manuel, de que as touradas são um "divertimento bárbaro, impróprio de nações civilizadas, que serve unicamente para habituar o homem ao crime e à ferocidade".

Estes argumentos têm sido amplificados por grupos e movimentos radicais, como o "veganismo", que pretendem não apenas pôr fim à festa de toiros, mas também a toda a cultura "antropocêntrica" e a qualquer relação utilitária com os animais por parte dos humanos, incluindo a alimentação (Fischler, 1992; Potts, 2017), dado que eles (ou pelo menos alguns deles, "pensam", possuem perceção da sua 
identidade, comunicam e sentem (são "sencientes"), o que, para além de os tornar sujeitos de um direito específico, como acontece já hoje na legislação portuguesa, lhes confere direitos e, no limite, os torna iguais aos humanos (Safina, 2016). O conhecido slogan "todos animais, todos iguais", utilizado por estes movimentos, traduz bem a filosofia que lhes subjaz.

Propõem, pois, uma deslocação da fronteira que separa, no que designam "culturas carnistas" ou antropocêntricas, os animais humanos e os animais não humanos. As culturas antropocêntricas estabelecem como linha de separação a capacidade de utilizar a razão de modo a controlar os instintos, produzir julgamentos éticos e morais, aprender de forma crítica, utilizar a língua para comunicar e pensar e atribuir sentido às coisas, isto é, construir cultura. Os movimentos animalistas e veganistas propõem uma outra linha divisória, mais ou menos arbitrária (Lira, 2013), que divide os animais entre os que sentem (os que possuem sistema nervoso central, incluindo os humanos) e os restantes.

Estes desenvolvimentos na filosofia animalista não anulam, antes incorporam, as acusações de anacronismo e violência gratuita dirigidas a certas práticas com animais, incluindo a chamada festa de toiros.

Argumentando que a tauromaquia corresponde a uma prática que incita à violência típica de povos menos civilizados, e procurando debilitá-la operando um corte geracional que retire as crianças do contacto com as corridas de toiros, os movimentos antitaurinos têm promovido, com algum sucesso, não apenas campanhas de inculcação ideológica de massas, mas também ações localizadas no sentido de interditar o acesso das crianças e jovens a manifestações práticas da cultura tauromáquica. Por exemplo, têm sido, de facto, várias as restrições legalmente impostas nos anos mais recentes para impedir a entrada das crianças em praças de toiros e têm-se igualmente multiplicado as denúncias à IGAC e à Comissão Nacional de Promoção dos Direitos e Proteção de Crianças e Jovens (CNPDPCJ) feitas por associações animalistas quando tomam conhecimento de eventos em que crianças com menos de 16 anos participam em treinos práticos de escolas de toureio, em treinos de forcados ou em treinos de praticantes do toureio a cavalo, de modo a impedir a sua realização mesmo que tenham lugar em quintas privadas e com reses de tamanho e idade adequados à idade e experiência dos aprendizes.

Segundo os animalistas, como se pode ver nos projetos de lei do PAN (181/XIII), do BE (217/XIII) e do PEV (251/XII) ${ }^{1}$ apresentados à Assembleia da República visando proibir, impedir ou restringir a participação de menores em

1 Projetos de lei votados e chumbados em 02 de junho de 2016. O projeto de lei do PAN foi rejeitado, com votos contra do PSD, do PS (em cuja bancada 11 deputados votaram a favor e outros 11 se abstiveram), do CDS-PP (à exceção de 1 que se absteve) e do PCP, e com votos a favor do BE, de Os Verdes, do PAN e dos já referidos 11 deputados do PS. O projeto de lei do BE foi rejeitado, com votos contra do PSD, do PS (11 deputados votaram a favor e 10 abstiveram-se), do CDS-PP e do PCP, votos a favor do BE, de Os Verdes, do PAN e de 11 deputados do PS. O projeto de lei do PEV foi rejeitado, com votos contra do PSD, do PS (9 deputados votaram a favor e 12 abstiveram-se), do CDS-PP e do PCP, e com votos a favor do BE, de Os Verdes, do PAN e 9 votos de deputados do PS. Em anos subsequentes, nomeadamente em 2018, seguiram-se iniciativas semelhantes e com destinos também análogos. 
touradas e eventos do género, essas restrições seriam, na sua perspetiva, medidas úteis, porque assistir a festas de toiros representaria um perigo para o normal desenvolvimento psicológico das crianças e, por conseguinte, para o futuro das sociedades. O mesmo argumento, expresso quase exatamente nos mesmos termos, apareceu na avaliação e recomendações feitas a Portugal pelo Comité dos Direitos das Crianças das Nações Unidas (CDCNU), concluído em janeiro 2014, relativo à "violência" associada aos espetáculos tauromáquicos e ao seu potencial efeito no desenvolvimento das crianças (CDCNU, 2014). ${ }^{2}$

O Comité dos Direitos das Crianças da ONU considera que em Portugal existe um grave problema de proteção das crianças em relação a putativos malefícios dos espetáculos tauromáquicos, onde podem presenciar atos de violência, mas também em relação às escolas de tauromaquia, onde as crianças são incitadas a participar diretamente nos referidos atos. Na resolução do Comité dos Direitos das Crianças das Nações Unidas pode ler-se, no ponto 37 das Recomendações a Portugal, que:

O Comité está preocupado com o bem-estar físico e mental das crianças envolvidas nos espetáculos tauromáquicos e representações associadas, bem como com o bem-estar mental e emocional das crianças que como espectadores estão expostas à violência das touradas.

e no ponto 38 que:

O Comité, tendo em vista a eventual proibição da participação de crianças em touradas, insta o Estado a tomar as medidas legislativas e administrativas necessárias, a fim de proteger todas as crianças envolvidas nos espetáculos tauromáquicos e representações associadas, bem como na sua qualidade de espectadores. Isso pode incluir o aumento da idade mínima de 12 anos para a formação, nomeadamente em escolas de toureio e quintas privadas e para a participação de crianças em touradas, bem como um aumento de 6 anos à idade mínima autorizada para as crianças assistirem a eventos como espectadores. O Comité também insta o Estado a tomar medidas de sensibilização sobre a violência física e mental associada às touradas e o seu impacto sobre as crianças.

Mas em nenhum dos casos se apresentou qualquer evidência empírica, baseada em qualquer estudo científico, do presumido malefício da tauromaquia para as crianças. Será que ele existe ou é apenas uma opinião do Comité dos Direitos das Crianças?

São, aliás, conhecidos dois trabalhos, ambos produzidos em Espanha, que apontam no sentido contrário.

Um primeiro resulta de um pedido de pareceres feito pelo Defensor del Menor en la Comunidad de Madrid dirigido a um conjunto de quatro equipas de

2 Em 2018 o mesmo CDCNU produziu recomendações à Espanha de teor semelhante, segundo noticia o jornal $A B C$ de 08 de fevereiro do mesmo ano. 
peritos independentes, sintetizados por Enrique Echeburua Odriozola, catedrático em Psicologia Clínica da Universidade do País Basco. A conclusão, vertida no último parágrafo, é a de que "no hay bases suficientes para sustentar cientificamente una medida como la prohibición de entrada de los menores de 14 años en las plazas de toros" (Odriozola, 1999: 15). O segundo consiste na tese de doutoramento de David Guillén defendida na EIDUNET, em Madrid, com o título Bienestar y Recursos Psicológicos en Alumnos de Escuelas Tauromáquicas (Guillén, 2017). Usando testes validados em psicologia, a tese conclui que os alunos que frequentam escolas de tauromaquia (tal como outros que praticam desportos que envolvem risco), comparados com os seus colegas nas escolas regulares, apresentam melhores índices de bem-estar e recursos psicológicos mais desenvolvidos para enfrentar os desafios do quotidiano.

Não se conhecem estudos realizados sobre o tema em Portugal. Assim, com base nas suas convicções, os aficionados à festa de toiros rejeitam a argumentação contrária à participação das crianças na festa de toiros e que a classifica como anacrónica e resultante do atraso civilizacional. Entre os argumentos centrais que utilizam conta-se o dos significados e valores da tauromaquia, emblema identitário das comunidades que praticam rituais taurinos. Valorizam as suas dimensões e funções simbólicas, sociais, culturais, ecológicas e económicas, exaltando valores como, entre muitos outros, a bravura, a solidariedade, a emoção estética associada à arte de lidar toiros em situações extremas de risco e a capacidade de superação do medo (Capucha, 2013). Entre as várias maneiras existentes de construir uma relação especial com o toiro de lide nenhuma é sádica, mas antes quase sagrada, dado o caráter totémico do animal, com o qual se mantém uma relação de grande proximidade, que é, de forma mais ampla, uma proximidade entre os homens, a natureza em geral e os animais em particular (Wolff, 2010; Albernaz, 2013).

De um lado e do outro procuram-se, pois, argumentos, num caso para proibir a festa e fazer crescer o número de adeptos da ideologia animalista, e do outro, de forma geralmente defensiva, para proteger o direito à identidade e à democracia cultural.

Mas não é a enumeração e a análise das razões de um e outro lado que nos ocupa aqui. Na verdade, não se pretende, neste artigo, colocar em contraste o argumentário anti e pró-taurino, nem avaliar os vários argumentos utilizados de um e outro lado, centrados uns na valorização da cultura e da identidade das comunidades humanas, e outros no evitamento do que dizem ser os efeitos negativos da tauromaquia sobre as crianças e o processo civilizacional, para além do alegado sofrimento animal. Sem pretensões de problematização teórica, procuramos apenas verificar se há alguma evidência empírica para sustentar os dois argumentos antitaurinos apresentados acima: que a tauromaquia releva do atraso de desenvolvimento e que perturba psicologicamente as crianças e o seu desenvolvimento por razões ligadas à violência.

\section{À procura de evidências}

Não escolhemos os dois tópicos que mencionámos, o do desenvolvimento e o da violência e seus efeitos psicológicos sobre as crianças, por acaso. É que, para além da 
sua centralidade no debate entre os que defendem e os que visam condicionar e pôr termo à festa de toiros, para ambos os tópicos existem indicadores que permitem aferir objetivamente, em Portugal, a existência dos impactos negativos da tauromaquia que se diz existirem.

A questão que as tomadas de posição antitaurinas colocam é a seguinte: se a tauromaquia releva de atrasos de desenvolvimento social e se, como prática violenta, tem efeitos psicológicos negativos para o crescimento psicologicamente equilibrado das crianças, então será de esperar que se encontrem nos concelhos com maior presença de aficionados às festas de toiros indicadores de menor desenvolvimento e de maior violência do que o normal na sociedade a que pertencem. O que se pretende no presente artigo é, então, verificar até que ponto as referidas ideias encontram suporte na realidade empírica, através de algumas constatações simples.

Usamos como aproximações ao nível de desenvolvimento e à violência, respetivamente, o índice de poder de compra (IPC) e a taxa de criminalidade (TC), ambos desagregados por concelho. No plano operacional, postulamos que, se existir uma correlação positiva estatisticamente relevante entre a tauromaquia e valores baixos nos indicadores de desenvolvimento e altos nos de violência, pode-se colocar a hipótese (embora não concluir, dado que a correlação não significa causalidade), que ela deve ser estudada no sentido de verificar os mecanismos que a tornam perniciosa à modernização e potencial causa de violência e criminalidade. Porém, se a correlação for nula, essas ideias não têm sustentação e devem ser tratadas como meras opiniões. Podem mesmo não passar de ideologia no sentido técnico do termo: ideias impostas apenas para defender interesses ou visões do mundo particularistas (Boudon, 1986). Claro está que, se a correlação for negativa, também não se poderá deduzir que a tauromaquia promove o desenvolvimento e a não violência, embora se pudessem abrir pistas para compreender melhor a relação entre tauromaquia e a modernidade na linha dos estudos desenvolvidos por Calvo (1989) ou por Elias (1992) sobre o papel dos jogos no controlo da violência.

Relativamente ao modo como a questão foi colocada no início do texto, nomeadamente no que toca às recomendações da ONU a Portugal a respeito da participação e assistência de crianças a eventos tauromáquicos, énecessário um esclarecimento adicional sobre a pertinência dos indicadores escolhidos, dado que eles não se referem especificamente a crianças. ${ }^{3}$ Socorremo-nos aqui de teorias sociológicas que fazem parte do acervo de conhecimentos consensualmente aceites na comunidade científica.

A maioria das pessoas socializadas em ambientes nos quais a tauromaquia possui uma presença forte e longa foram, enquanto crianças, expostas à assistência aos mais variados festejos taurinos, salvo eventuais situações, muito improváveis, de total substituição populacional. Ora, como sintetizou Giddens (2004: 26), “a socialização é o processo através do qual as crianças, ou outros novos membros da

3 Também não pretendemos utilizar o argumento, baseado apenas na experiência dos autores, de que não há registo da maior prevalência de atos violentos por parte das crianças que participam em festas com reses bravas, nem tão-pouco alguma vez se registaram casos de crianças fisicamente postas em risco ou de qualquer modo acidentadas nessas mesmas festas, incluindo aulas práticas de toureio. 
sociedade, aprendem o modo de vida da sociedade em que vivem. Este processo constitui o principal canal de transmissão da cultura através do tempo e das gerações". Como explica Bourdieu (1980: 88), "os condicionamentos associados a uma classe particular de condições de existência produzem habitus, sistemas de disposições duráveis e transponíveis, estruturas estruturadas predispostas a funcionar como estruturas estruturantes, quer dizer, enquanto princípios geradores e organizadores de práticas e de representações [...]" (tradução dos autores). Bernard Lahire (2004: 17), por seu turno, ajuda-nos a perceber como as variações interindividuais resultam, por um lado, da pluralidade das disposições e competências culturais incorporadas, "supondo-se a pluralidade de experiências socializadoras em matéria cultural" e, por outro lado, da diversidade de contextos culturais onde ocorrem as práticas e as escolhas dos indivíduos.

São, portanto, teorias sociológicas bem consolidadas as que nos permitem postular que, se no seu passado enquanto crianças as pessoas que são abrangidas pelas estatísticas sobre o índice de poder de compra e pelas taxas de criminalidade tivessem sido afetadas negativamente pelo contacto com a violência e o anacronismo das festas taurinas, isso se refletiria no presente em valores mais baixos do índice de consumo e mais altas taxas de criminalidade.

É certo que as populações mudam, de modo que nem todos os residentes num concelho são os que nele foram crianças. Assim, aqueles que hoje entram nas estatísticas de cada concelho podem não ter todos passado pelas mesmas experiências em crianças. Mas não é menos certo que os movimentos migratórios não têm, geralmente, a amplitude suficiente para transfigurar as populações concelhias de tal modo que em cada geração a maioria dos agregados domésticos se renovassem completamente. Para além do que as comunidades recetoras socializam os que se integram, pelo menos parcialmente. O exercício que aqui se apresenta não perde, por isso, validade.

Operacionalmente, a questão a que se pretende responder é, portanto, se nas comunidades com maior densidade taurina existe maior criminalidade violenta do que nas restantes, o que poderia ser sinal de perturbações psicológicas resultantes da presença da tauromaquia, e se estas comunidades são menos desenvolvidas, possuindo por isso menor poder de compra, do que a média nacional. Sinteticamente, a hipótese colocada é a de que, a ser verdade o que dizem as acusações antitaurinas, se pode esperar que nos concelhos onde é maior a presença da tauromaquia seja menor o poder de compra e maior o número de ocorrências de comportamentos violentos.

\section{Metodologia}

Para proceder à verificação da hipótese, primeiro foi preciso encontrar um indicador da prevalência da tauromaquia em cada concelho português.

Recorrendo ao desenvolvimento de uma metodologia já utilizada num estudo anterior (Pereira, 2010), o primeiro passo para encontrar esse indicador, a que chamaremos índice de atividade tauromáquica (IAT), foi encontrar nos registos oficiais (nomeadamente na Inspeção Geral das Atividades Culturais) o número e 
Quadro 1 Ponderação da frequência das dimensões que integram o IAT em Portugal

\begin{tabular}{ccccccc}
\hline Registos $\left(\mathrm{n} .{ }^{\circ}\right)$ & T.Pop & RET & Praças & Ganadarias & Forcados & Artistas \\
\hline 0 & 0 & 0 & 0 & 0 & 0 & 0 \\
$\geq 1$ & 10 & 10 & 5 & 1 & 10 & 1 \\
$\geq 2$ & 20 & 15 & 10 & 5 & - & 4 \\
$\geq 5$ & 30 & 20 & - & 10 & - & 7 \\
$>10$ & 30 & 30 & - & - & & 10 \\
\hline
\end{tabular}

tipo de festejos taurinos realizados no país. O IAT traduz a "densidade taurina", um indicador da presença de elementos relevantes da tauromaquia num determinado território concelhio. Variando entre um valor máximo nos concelhos onde a tauromaquia é um "fenómeno social total" (Mauss, 1989 [1950]), e um valor nulo nos casos em que não há vestígios da presença atual de elementos tauromáquicos relevantes, a uma maior densidade corresponde um IAT maior, isto é, uma maior presença desses elementos.

No ano de 2014 (os números para este ano variam de forma muito ligeira nos anos seguintes, nomeadamente aqueles a que se referem as estatísticas sobre o poder de compra - 2015 - e a criminalidade - 2016) identificou-se um total de 1248 eventos taurinos no país, incluindo 231 espetáculos em praças de toiros nas diversas modalidades previstas no Regulamento de Espetáculos Tauromáquicos (RET) e 1017 manifestações tauromáquicas populares (T. Pop), como largadas e/ou esperas de toiros, touradas à vara larga, vaca das cordas (Ponte de Lima), capeia arraiana, touradas à corda, vacadas, "pamplonas" ou garraiadas, entre outras. Seguidamente identificaram-se os concelhos onde existem praças de toiros fixas (Praças), ganadarias bravas (Ganadarias), grupos de forcados (Forcados) e artistas tauromáquicos residentes (Artistas).

Cada uma destas dimensões foi depois objeto da atribuição de um score em função da frequência em que ocorrem, como se mostra no quadro 1. Para cada dimensão atribui-se um valor cuja escala varia entre 0 a 40, 0 a 30 e 0 a 10, em função do número de ocorrências. O valor máximo do score é 110.

O terceiro passo consistiu em atribuir um peso específico a cada uma das dimensões, o qual multiplicado pelo score alcançado através da frequência com que ocorre cada uma das dimensões leva à obtenção de um valor para cada dimensão. O índice de atividade tauromáquica corresponde ao somatório do valor obtido em cada dimensão, ponderado pelo peso atribuído a cada uma delas. Obtém-se assim a matriz apresentada no quadro 2 .

Para ajudar à leitura a fazer do quadro 2, dá-se o seguinte exemplo: um concelho com tauromaquias populares (T.Pop) entre 2 e 4 registos, com 1 espetáculo em praça (RET), uma praça de toiros fixa (Praças), nenhuma ganadaria (Ganadarias), 1 grupo de forcados (Forcados) e entre 5 e 10 artistas tauromáquicos residentes (Artistas), regista 4 pontos na primeira dimensão, 2 pontos na segunda, 0,5 na terceira, 0 na quarta, 2 na quinta e 1,4 na sexta. Somará no total 9,9 pontos numa escala de 0 a 20 . 
Quadro 2 Valores a considerar na construção do IAT por concelho

\begin{tabular}{|c|c|c|c|c|c|c|}
\hline \multirow{2}{*}{$\begin{array}{l}\text { Registos } \\
\left(\mathrm{n} .^{\circ}\right)\end{array}$} & $20 \%$ & $20 \%$ & $10 \%$ & $10 \%$ & $20 \%$ & $20 \%$ \\
\hline & T.Pop & RET & Praças & Ganadarias & Forcados & Artistas \\
\hline 0 & 0,0 & 0,0 & 0,0 & 0,0 & 0,0 & 0,0 \\
\hline$\geq 1$ & 2,0 & 2,0 & 0,5 & 0,1 & 2,0 & 0,2 \\
\hline$\geq 2$ & 4,0 & 3,0 & 1,0 & 0,5 & - & 0,8 \\
\hline$\geq 5$ & 6,0 & 4,0 & - & 1,0 & - & 1,4 \\
\hline$>10$ & 8,0 & 6,0 & - & - & - & 2,0 \\
\hline
\end{tabular}

Quadro 3 Níveis agregados de presença tauromáquica

\begin{tabular}{ccc}
\hline Grupos & Presença tauromáquica & Nivel \\
\hline 0 & Inexistente & 0 \\
0,1 a 4 & Fraca & 1 \\
4,1 a 9 & Relevante & 2 \\
9,1 a 14,9 & Forte & 3 \\
15 a 20 & Muito Forte & 4 \\
\hline
\end{tabular}

A fórmula apresentada foi aplicada aos registos existentes para todos os concelhos. Seguidamente, para simplificação da leitura dos dados, os concelhos foram agrupados em cinco níveis de atividade tauromáquica, como consta no quadro 3.

Em quinto e último lugar cruzou-se o IAT, em cada concelho e em cada NUT III do país, com os registos fornecidos pelo INE, por um lado relativos ao índice do poder de compra concelhio (INE, 2015) e, por outro lado, relativos à taxa de criminalidade (INE, 2016). Se os índices de presença da tauromaquia permitem aferir a proximidade das populações em relação ao fenómeno tauromáquico, o índice de poder de compra e a taxa de criminalidade são aproximações, como vimos, respetivamente à presença de anacronismos e atrasos de desenvolvimento e à geração de violência provocada pela proximidade com a tauromaquia.

\section{Principais resultados}

Comecemos por olhar o mapa de Portugal Continental segundo o IAT. Olhando num plano mais agregado, talvez com alguma surpresa, verificamos que apenas na NUT III Vale do Ave, não se regista, no Continente, qualquer presença de atividade tauromáquica. O mesmo acontece nas NUT III insulares de Santa Maria, São Miguel, Pico, Faial, Flores, Corvo e Madeira (a Ilha de Porto Santo regista um IAT de nível 1 - fraco).

A este nível, as regiões de intensidade máxima apanham a Ilha Terceira, toda a região Oeste, a área metropolitana de Lisboa, a península de Setúbal, quase todo o Ribatejo e quase todo o Alentejo (Alto e Baixo) O Litoral Alentejano, como quase toda a região Centro, está num nível imediatamente abaixo, de intensidade forte 
(nível 3). No nível 2, de intensidade relevante, está o Algarve, a parte mais a norte do Centro, quase todo o Minho, o Douro Litoral e a parte oeste de Trás-os-Montes.

Uma análise mais fina, ao nível concelhio, altera este panorama, fortemente afetado pela presença em muitas das mencionadas regiões classificadas como "relevante" e "forte" de concelhos com atividade tauromáquica mais intensa.

A mancha a nível concelhio revela que em grande parte do Algarve, em três concelhos alentejanos, e também na maior parte do território no Norte e no Centro, a atividade tauromáquica é nula. Pelo contrário, ela é fortíssima em Alcochete, Angra do Heroísmo (que não aparece no mapa, o qual não inclui as regiões autónomas), Benavente, Coruche, Évora, Monforte, Montijo, Moita do Ribatejo, Moura e Vila Franca de Xira.

A forte presença do fenómeno taurino no Ribatejo, na área metropolitana de Lisboa, na região Oeste e no Alentejo é mais nítida ao verificarmos que se encontram aí também vários concelhos com nível de intensidade tauromáquica "forte", como são os casos de Alandroal, Alenquer, Almeirim, Arronches, Arruda dos Vinhos, Azambuja, Barreiro, Beja, Caldas da Rainha, Chamusca, Cuba, Elvas, Estremoz, Mafra, Marvão, Mourão, Montemor-o-Novo, Nisa, Palmela, Portalegre, Portel, Redondo, Reguengos de Monsaraz, Salvaterra de Magos, Santarém, Seixal, Sobral de Monte Agraço, Torres Novas, Torres Vedras, Viana do Alentejo, e Vila Viçosa. Com o mesmo nível, mas fora destas áreas, encontramos os casos da Praia da Vitória, de Santa Cruz da Graciosa e de Velas, todos nos Açores, e ainda do Sabugal.

Concelhos com um nível "relevante", no qual se encontram casos tão notáveis como Barrancos, Montalegre, Nazaré, Póvoa do Varzim ou Setúbal, para apenas citar alguns, encontram-se ou dispersos pelo território ou próximos das mesmas regiões com maior densidade taurina.

Resta-nos agora, de acordo com a metodologia mencionada, relacionar o índice de atividade tauromáquica por concelho com o índice de poder de compra e com as taxas de criminalidade divulgados, com desagregação concelhia, pelas entidades estatísticas oficiais de Portugal.

Relembramos que ao avaliar a correlação entre dois fenómenos, como, neste caso, as variáveis representativas de atividade tauromáquica e os indicadores de criminalidade, por um lado, e de desenvolvimento, por outro lado, não estamos a postular uma relação de causa-efeito. Estamos apenas a registar a ocorrência simultânea dos fenómenos de que os indicadores estatísticos dão conta. Como se disse atrás, não procuramos estabelecer uma relação de causalidade, mas apenas explorar, com base em indicadores empíricos e não em preconceitos ideológicos, a existência, ou não, de uma correlação entre os dois conjuntos de indicadores (tauromaquia e desenvolvimento; tauromaquia e violência/cri- minalidade).

No sentido de verificar se existe alguma relação, optamos nesta análise por fazer o estudo da correlação. ${ }^{4}$

4 Em análises estatísticas, utiliza-se muitas vezes a correlação, para verificar a existência ou não, de uma relação entre duas ou mais variáveis. Isto é, pretende-se saber se as alterações sofridas por uma variável, são acompanhadas por alterações na outra variável. 


$\begin{array}{ll}\text { Legenda } \\ 4 \\ 3 & \square \\ 2 & \square \\ 1 & \square \\ 0 & \square \\ \text { n.d. }\end{array}$

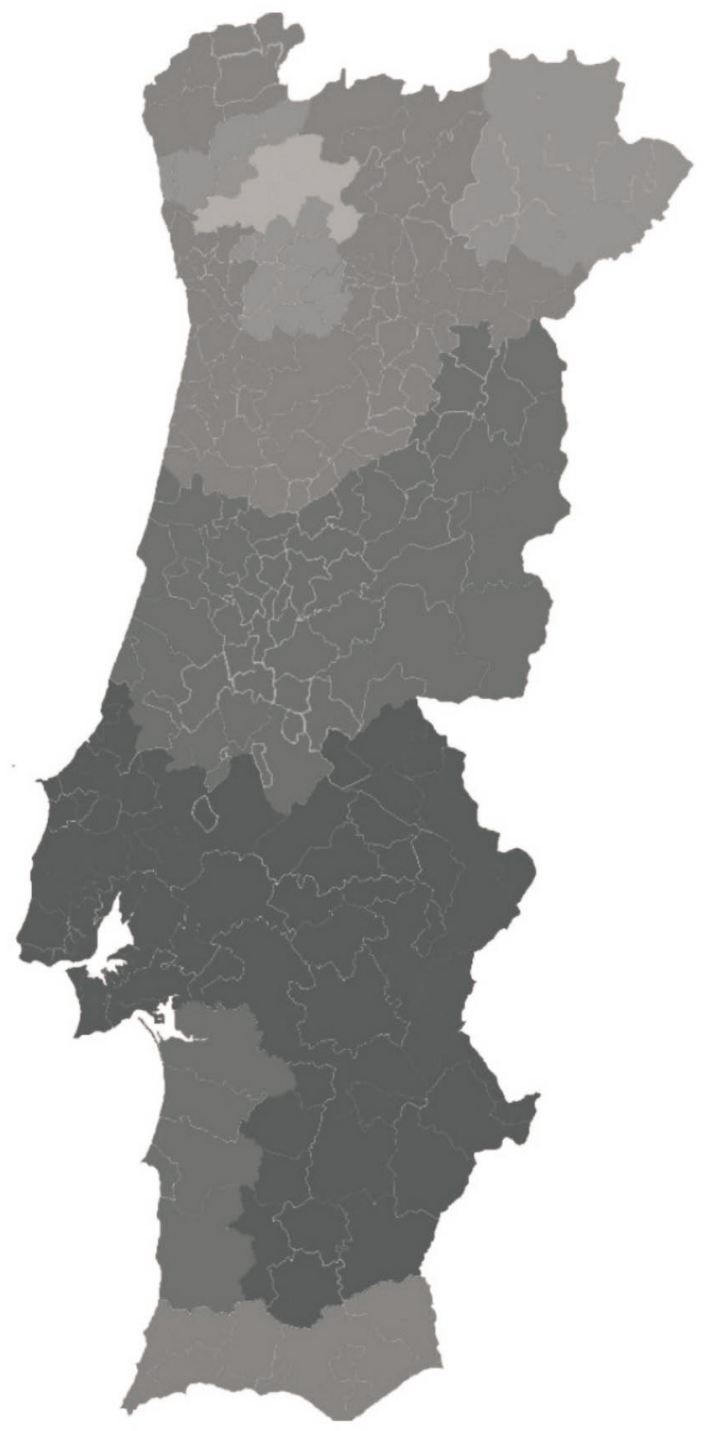

Figura 1 IAT no Continente, por NUT III, 2014

Fonte: Cálculos próprios com base dos dados do IGAC. 


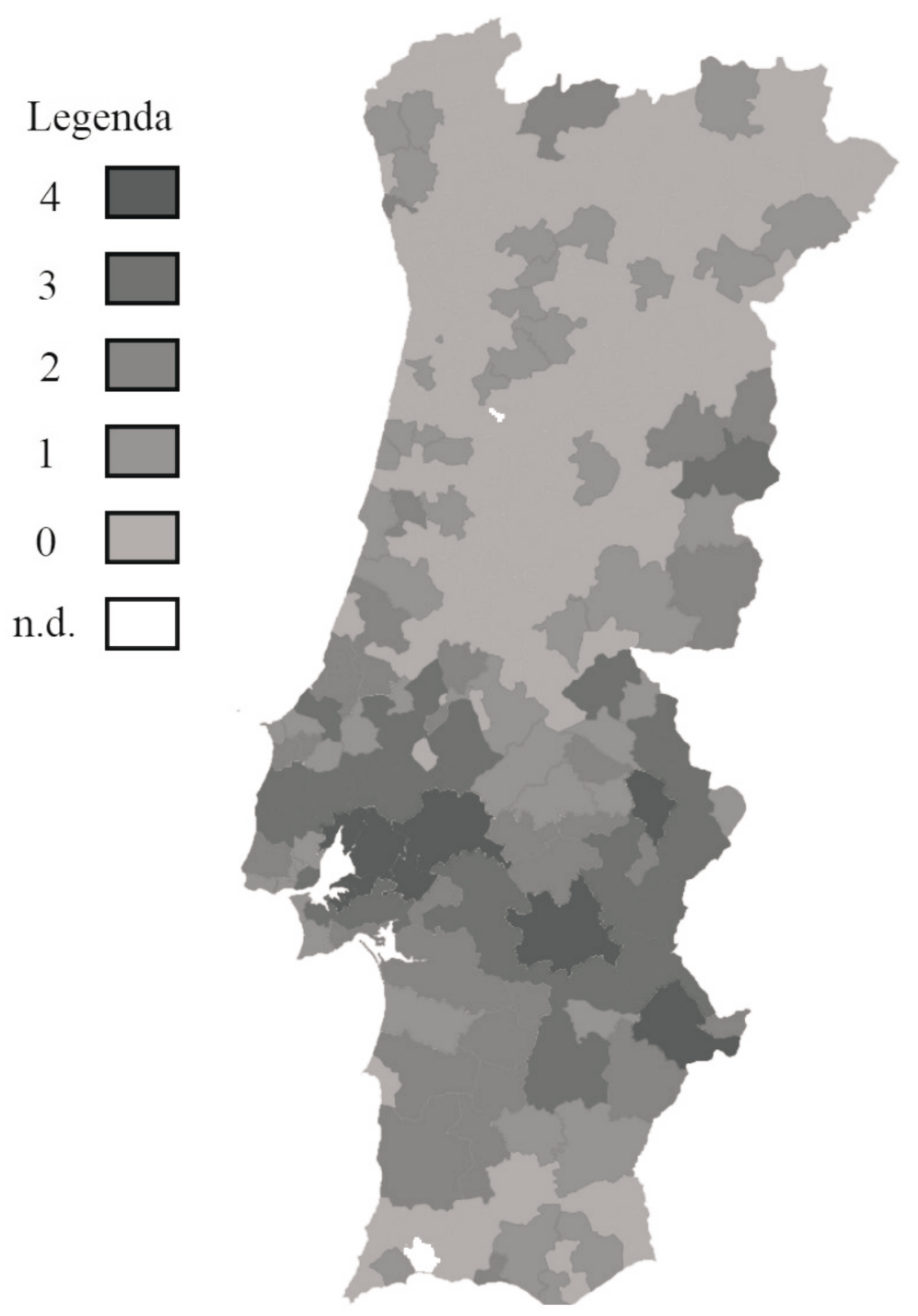

Figura 2 IAT no Continente por concelho, 2014

Fonte: Cálculos próprios com base dos dados do IGAC. 
Quadro 4 Correlação entre o IAT, a TC (total e por alguns tipos de crime) e o IPC

\begin{tabular}{|c|c|c|c|c|c|c|c|c|c|}
\hline \multicolumn{7}{|c|}{ Taxas de criminalidade -2014} & \multicolumn{3}{|c|}{ IPC } \\
\hline & $\begin{array}{c}\text { Taxa de } \\
\text { criminalidade }(\% \circ) \\
\text { Total }\end{array}$ & $\begin{array}{c}\text { Crimes } \\
\text { contra a } \\
\text { integridade } \\
\text { física }\end{array}$ & $\begin{array}{c}\text { Furto/roubo } \\
\text { por esticão } \\
\text { e na via } \\
\text { pública }\end{array}$ & $\begin{array}{l}\text { Furto de } \\
\text { veículo e } \\
\text { em veículo } \\
\text { motorizado }\end{array}$ & $\begin{array}{c}\text { Condução } \\
\text { de veículo com } \\
\text { taxa de álcool } \\
\text { igual ou superior } \\
\text { a } 1,2 \mathrm{~g} / \mathrm{l}\end{array}$ & $\begin{array}{c}\text { Crimes } \\
\text { contra o } \\
\text { património }\end{array}$ & $\begin{array}{c}\text { IPC } \\
2009\end{array}$ & $\begin{array}{l}\text { IPC } \\
2011\end{array}$ & $\begin{array}{c}\text { IPC } \\
2013\end{array}$ \\
\hline IAT & 0,0 & $-0,1$ & 0,1 & 0,0 & $-0,1$ & 0,1 & 0,3 & 0,2 & 0,2 \\
\hline
\end{tabular}

Fontes: INE.

Conforme mostra o quadro 4, os valores da correlação entre as variáveis que indicam a presença da tauromaquia nos concelhos e, por um lado, a taxa de criminalidade (na sua totalidade e parcialmente com os crimes contra a integridade física, por furto/roubo por esticão e na via pública, por furto de veículo e em veículo motorizado, por condução de veículo com taxa de álcool igual ou superior a 1,2 g/l, e contra o património), por outro lado, variam entre -0,1 e 0,1, conforme o tipo de crime. A correlação é, portanto, nula.

Quanto à correlação entre a presença da tauromaquia em cada concelho do país e o índice de poder de compra, cujos valores são 0,3 em 2009, 0,2 em 2011 e os mesmos 0,2 em 2013, pode dizer-se que ela é fraca.

\section{Conclusões}

Os valores da correlação apurados entre o índice de atividade tauromáquica por concelho e os indicadores de criminalidade, bem como o índice de poder de compra, são nulos ou muito fracos. Significa isto que não se regista a ocorrência simultânea dos fenómenos avaliados por estes indicadores estatísticos. Portanto não existe uma correlação entre a presença forte de atividade tauromáquica ao nível dos concelhos portugueses, e as respetivas taxas de criminalidade e índice de poder de compra. O estudo não revela, por isso, qualquer sustentação empírica da ideia de que a participação na festa de toiros provoca perturbações mentais conducentes à violência, nem que se associe a maior ou menor desenvolvimento das comunidades onde ela tem lugar. A demonstração de ausência de correlação não sustenta os argumentos antitaurinos.

\section{Referências bibliográficas}

Albernaz, Lady Selma (2013), “Festa brava portuguesa: pessoas humanas e pessoas animais", Anthropológicas, 24 (1), pp. 181-203.

Boudon, Raymond (1986), L'Idéologie. L'Origine des Idées Reçues, Paris, Librairie Arthème Fayard. 
Bourdieu, Pierre (1980), Le Sens Pratique, Paris, Les Editions de Minuit.

Calvo, Enrique Gil (1989), Función de Toros, Madrid, Espasa-Calpe.

Capucha, Luís (2013), “Festa de Toiros”, Anthropológicas, 24 (1), pp. 145-179.

CDCNU - Comité dos Direitos das Crianças das Nações Unidas (2014), Relatório de Avaliação da Convenção dos Direitos das Crianças. Recomendações a Portugal, Nova Iorque, CDCNU.

Dos Santos, Júlio Eduardo, Alfredo Vidigal das Neves e Castro, e Rodrigo Guerra Álvares Cabral (1933), A Momentosa Questão dos "Touros de Morte" em Portugal, relatório elaborado pelos delegados das Sociedades Protetoras dos Animais, de Lisboa e Porto, e Liga Nacional de Defesa dos Animais, na comissão nomeada pelo Governo, por portaria de 6 de maio de 1933, lavrada em harmonia com o disposto no artigo $1 .^{\circ}$ do decreto-lei n. ${ }^{\circ} 22.482$.

Elias, Norbert (1992), A Busca da Excitação, Lisboa, Difel.

Fischler (1992), L'Homnivore, Paris, Odile Jacob.

Giddens, Anthony (2004), Sociologia, Lisboa, Fundação Caloust Gulbenkian (4. a edição).

Guillaume-Alonso, Araceli (1999), “Contre la corrida: essai de typologie des positions anti-taurines, XVIe-XVIIe siècles", em Annie Molinié-Bertrand, Jean-Paul Duviols e Araceli Guillaume-Alonso, Des Taureaux et des Hommes, Paris, Presses de l’Université de Paris-Sorbonne, pp. 13-22.

Guillén, David (2017), Bienestar y Recursos Psicológicos en Alumnos de Escuelas de Tauromaquia, s.l., EIDUNED, tesis doctoral.

INE - Instituto Nacional de Estatística (2015), Estudo sobre o Poder de Compra Concelhio 2015, Lisboa, INE.

INE - Instituto Nacional de Estatística (2016), Taxa de Criminalidade por Localização Geográfica e Categoria de Crime, disponível em: www.ine.pt (dados atualizados a 10 de outubro de 2016).

Lahire, Bernard (2004), La Culture des Individus. Dissonances Culturelles et Distinction de Soi, Paris, Edition la Découverte.

Lira, Luciana Campelo (2013), “O outro lado do muro: natureza e cultura na ética animalista e no ativismo vegan", Anthropológicas, 24 (1), pp. 67-102.

Mauss, Marcel (1989 [1950]), Sociologie et Anthropologie, Paris, Quadrige/Presses Universitaires de France.

Odriozola, Enrique Echeburua (1999), “Valoración de los estudios realizados, recomendaciones específicas y conclusiones", em Javier Urra, Defensor del Menor en la Comunidad de Madrid, Posibles Repercusiones Psicológicas de las Corridas de Toros en Niños Menores, Madrid, Defensor del Menor en la Comunidad de Madrid.

Pereira, Luís (2010), Tauromaquia. Identidade Cultural, Enquadramento Legal e Desenvolvimento, Lisboa, ISCTE, tese de mestrado em Desenvolvimento, Diversidades Locais e Desafios Mundiais.

Potts, Annie (org.) (2017), Meat Culture, Leiden, Brill.

Safina, Carl (2016), Para Lá das Palavras. O que Pensam e Sentem os Animais, Lisboa, Relógio d'Água Editores.

Wolff, Francis (2010), Filosofía de las Corridas de Toros, Barcelona, Ediciones Bellaterra. 
Luís Capucha. Docente no Instituto Universitário de Lisboa, ISCTE-IUL, e investigador no Centro de Investigação e Estudos de Sociologia, CIES-IUL. E-mail: luis.capucha@iscte-iul.pt

Luís Pereira. Mestre em Desenvolvimento, Diversidades Locais e Desafios Mundiais, ISCTE-IUL. E-mail: luis.pereira.61@gmail.com

Tiago Tavares. Master in Finance pelo INDEG/ISCTE.

E-mail: tiagovargastavares@iol.pt

Receção: 01 de agosto de 2017 Aprovação: 24 de maio de 2018 